\title{
Body imaging: Diagnosis
}

\begin{abstract}
Authors:
Shalendra K. Misser ${ }^{1}$

Dion B. Steer ${ }^{2}$

Stephen Purcell ${ }^{3}$

Affiliations:

${ }^{1}$ Lake Smit and Partners Inc,

Durban, South Africa

${ }^{2}$ Alberlito Hospital, Ballito,

South Africa

${ }^{3}$ Hainsworth, Purcell and Associates Inc, Durban,

South Africa

\section{Correspondence to:}

Shalen Misser

Email:

misser@lakesmit.co.za

Postal address:

Private Bag X08, Overport

4067, Durban, KwaZulu-

Natal, South Africa

How to cite this article:

Misser SK, Steer DB, Purcell

S. Body imaging: Diagnosis.

S Afr J Rad. 2014;18(1); Art.

\#625, 3 pages. http://dx.doi.

org/10.4102/sajr.v18i1.625
\end{abstract}

\section{Copyright:}

(C) 2014. The Authors.

Licensee: AOSIS

OpenJournals. This work

is licensed under the

Creative Commons

Attribution License.

We congratulate Dr Ian Haynes from Pietermaritzburg for his spot-on diagnosis for which he will receive the prize of R1000 sponsored by RSSA. Drs Misser et al. elaborate on the findings and provide a brief discussion.

A 38-year-old woman presented with a painful left paramedian infra-umbilical abdominal wall mass. She is a keen athlete and is otherwise well. These are her ultrasound images and magnetic resonance imaging (MRI) sequences (after gadolinium administration).

\section{Answer}

The ultrasound images (Figures 1 and 2) demonstrate a spindle-shaped soft tissue mass of low central echogenicity, located at the medial margin of the left rectus abdominus muscle. The colour duplex sonar image reveals differential vascularity at the various aspects of the lesion. At the time of the sonar, we performed an ultrasound-guided biopsy of the lesion. In order to avoid peritoneal breach, a tangential caudocranial trajectory of the biopsy needle was employed. Three passes were made through the less vascular aspect of the lesion.

Figures 3 and 4 are axial and coronal post-gadolinium magnetic resonance (MR) images showing the intense enhancement pattern of the mass limited to the abdominal wall with no associated peritoneal or visceral abnormality. The transverse signal abnormality related to previous Pfannenstiel incision for caesarean section was noted. No synchronous lesions were identified.

Based on the location of the lesion, sonar features and MRI enhancement pattern, the principal radiological diagnosis was that of a desmoid tumour of the left rectus muscle. In fact, the initial sonar-guided core biopsy specimen was reported as a benign desmoid tumour. In light of the persistent cyclical pain and impact on the patient's activities, including sport, an excision of the mass was performed. The margins were complete and the lesion, measuring $2 \times 1.8 \times 1.5 \mathrm{~cm}$,

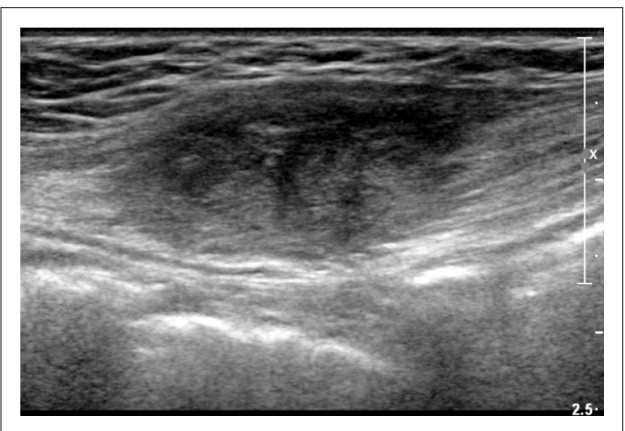

FIGURE 1: Sagittal B-mode sonar image.

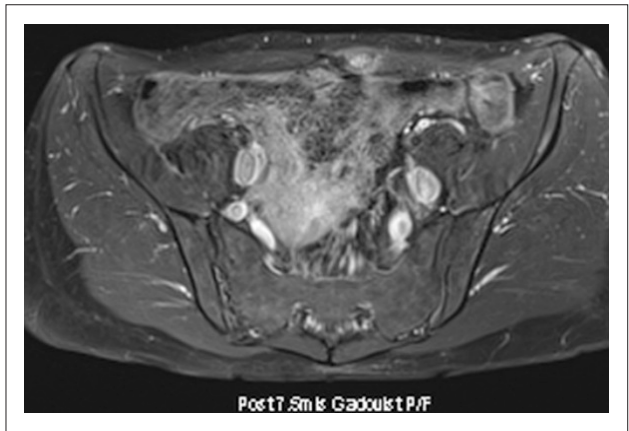

Post-gd, post-gadolinium

FIGURE 3: Axial post-gd T1 weighted image through lesion.

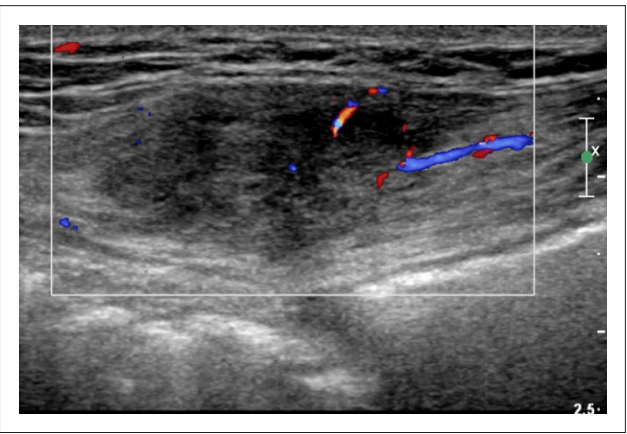

FIGURE 2: Sagittal colour duplex sonar image.

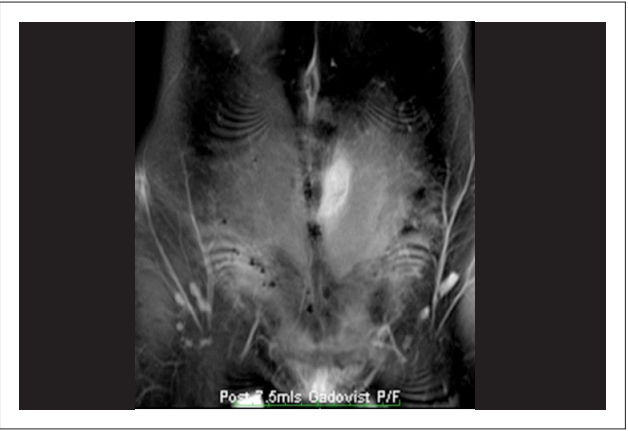

Post-gd, post-gadolinium

FIGURE 4: Coronal post-gd T1 weighted image. 
had a peculiar increased vascularity in the central part of the specimen relative to the rest of the tumour.

Microscopic pathologic assessment (Figure 5) confirmed, in addition to a background fibromatous stroma, the presence of endometrial tissue within the lesion. This included the presence of cysts and/or endometrial glands lined by tall columnar endometrial cells associated with a small amount of surrounding endometrial stroma. Some of the cysts were haemorrhagic. Surrounding mixed inflammatory cell infiltrate was present, including oedematous fibrous connective tissue stroma with lipid-laden macrophages.

In retrospect it was noted that the patient had had a previous caesarean section, which predisposed her to endometrial seeding. The final diagnosis was abdominal wall endometriosis with surrounding fibrosis.

\section{Discussion}

Endometriosis is a fairly common entity in women of childbearing age, occurring in $10 \%$ of the population, and is defined as the presence of normal endometrial tissue outside of the uterine cavity. ${ }^{1}$ These extra-uterine deposits of endometrium usually settle in the pelvis around the ovary or broad ligament. Extrapelvic sites are uncommon but increasingly being recognised. Abdominal wall endometriosis (AWE) is one example of extrapelvic endometriosis, accounting for $0.5 \%-4.0 \%$ of all cases of endometriosis. AWE is identified by the triad described by Esquivel-Estrada et al., ${ }^{2}$ consisting of periodic pain, associated with menses, history of caesarean section, and tumour inside a surgical scar confirmed as endometrium after histopathologic examination. AWE usually develops in relation to a previous surgical scar and should be considered in the differential diagnosis of any young adult female patient with an abdominal wall mass. With increasing numbers of surgical obstetric deliveries by caesarean section, the incidence of AWE is increasing and likely to be more frequently identified. AWE may develop months or years following the surgery. Pelvic endometriosis may not necessarily be present in the setting of AWE and is therefore not a prerequisite for the diagnosis. ${ }^{3}$

Symptoms associated with endometriosis may mimic other abdominal wall lesions (Table 1), therefore a definitive preoperative diagnosis is not always easy in every case. In Horton's series, ${ }^{3}$ the majority presented with mass, pain or less likely, cyclical symptoms. The major differential diagnoses include desmoid tumour, haematoma, abscess, neoplasm or injection-related granuloma. Desmoid tumour, also known as aggressive fibromatosis, is the primary differential diagnosis. There are several subtypes of desmoid tumours, including those associated with familial adenomatous polyposis (Gardner's) syndrome. The pain in AWE is typically cyclical but may be constant or lesions may be painless. This makes differentiation from desmoid tumours difficult clinically.

On ultrasound, AWE demonstrates heterogeneous reduced echogenicity with internal vascularity on colour duplex and power Doppler imaging. ${ }^{4}$ Desmoid tumours are more homogeneous in echo texture and seldom show increased vascularity. Computed tomography (CT) scans show wellcircumscribed masses of isodensity to muscle in both cases. Abscesses may demonstrate lower central attenuation of $<20 \mathrm{HU}$.

The MRI signal of endometriomas varies depending on the cystic component. AWE usually shows iso-intense to hyperintense signal on both T1 and T2 weighted sequences relative to muscle. Table 2 describes the MRI appearances of AWE and the major differential diagnoses. Atypical AWE, which resembles cystic ovarian endometriomas, may have

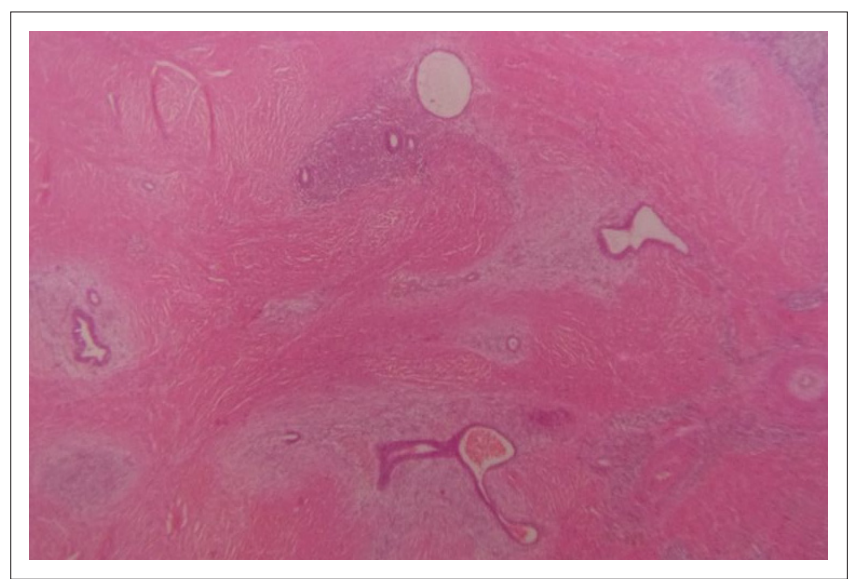

FIGURE 5: Microscopy of the mass - Haematoxylin and eosin stain (x 50 magnification).

TABLE 1: Differential diagnosis of anterior abdominal wall masses.

\begin{tabular}{|c|c|}
\hline Patho-mechanism & Diagnoses \\
\hline $\begin{array}{l}\text { Congenital and/or } \\
\text { genetic }\end{array}$ & $\begin{array}{l}\text { Familial adenomatous polyposis or Gardner's syndrome - } \\
\text { desmoid tumours (= aggressive fibromatosis) }\end{array}$ \\
\hline $\begin{array}{l}\text { Infective and/or } \\
\text { inflammatory }\end{array}$ & $\begin{array}{l}\text { Abscess } \\
\text { Myositis }\end{array}$ \\
\hline Neoplastic & $\begin{array}{l}\text { Metastatic disease } \\
\text { Granular cell tumour } \\
\text { Lymphoma } \\
\text { Sarcomas } \\
\text { Neurofibromas and nerve sheath tumours }\end{array}$ \\
\hline $\begin{array}{l}\text { Traumatic and/or } \\
\text { vascular }\end{array}$ & $\begin{array}{l}\text { Haematoma } \\
\text { Varices } \\
\text { Pseudo-aneurysm of inferior epigastric artery }\end{array}$ \\
\hline latrogenic & $\begin{array}{l}\text { Injection granuloma or suture granuloma } \\
\text { Surgical scar endometriosis } \\
\text { Incisional hernia }\end{array}$ \\
\hline
\end{tabular}

TABLE 2: MRI features of the major differential diagnoses.

\begin{tabular}{llll}
\hline Diagnosis & T1 signal relative to muscle & T2 signal relative to muscle & Post-gadolinium \\
\hline AWE & Iso-intense to mildly hyperintense & Iso-intense to hyperintense & Moderate diffuse enhancement \\
Desmoid tumour & Low to iso-intense & Hyperintense (later iso-intense) & Moderate to avid enhancement \\
Abscess & Low to iso-intense & Hyperintense & Rim enhancement \\
Sarcoma & Hypointense & Hyperintense & Heterogeneous enhancement \\
\hline
\end{tabular}

MRI, magnetic resonance imaging; AWE, abdominal wall endometriosis. 
T1 weighted uniform hyperintensity and T2 weighted low signal. Desmoid tumours are generally hyperintense to muscle on T2 weighted images, but as they mature with increasing collagenous component, the T2 signal decreases and approximates skeletal muscle.

Fluorodeoxyglucose (FDG) positron emission tomography (PET) scanning has only been described in a few reports for assessment of endometriomas. Most of the described lesions appear photopenic with reduced tracer uptake.

The management of AWE includes conservative pharmacotherapy using hormonal agents or surgical excision. ${ }^{5}$ Progestogen drug therapy is usually only beneficial in controlling symptoms temporarily, with recurrence on cessation of therapy. Surgical extirpation after confirmation of diagnosis on fine needle or core biopsy is the recommended treatment of choice. Recurrence after surgery is generally not expected.

AWE is becoming more frequently diagnosed because of the increasing awareness of this condition and the increasing number of caesarean section deliveries. It is the radiologist who should raise the alarm when sonar imaging of a mass in the anterior abdominal wall close to a surgical scar reveals heterogeneous echo and increased vascularity. Although there remains a wide list of differential diagnoses, the possibility of AWE should always be raised.

\section{Acknowledgements Competing interests}

The authors declare that they have no financial or personal relationship(s) that may have inappropriately influenced them in writing this article.

\section{Authors' contributions}

S.K.M. (Lake Smit and Partners Inc) was responsible for concept design, literature search, manuscript preparation and review. D.B.S. (Alberlito Hospital) was involved in manuscript review and definition of intellectual content. S.P. (Haisworth, Purcell and Associates Inc) was involved in histopathological slide preparation and manuscript editing.

\section{References}

1. Stein L, Elsayes KM, Wagner-Bartak M. Subcutaneous abdominal wall masses: Radiological reasoning. AJR. 2012;198:W146-151. http://dx.doi.org/10.2214/ AJR.10.7238

2. Esquivel-Estrada V, Briones-Garduño JC, Mondragón-Ballesteros R. Endometriosis implant in caesarean section surgical scar. Cir Cir. 2004;72(2):113-115. http:// dx.doi.org/10.1016/j.amjsurg.2007.07.035

3. Horton JD, DeZee KJ, Ahnfeldt EP, Wagner M. Abdominal wall endometriosis: A surgeon's perspective and review of 445 cases. Am J Surg. 2008;196:207-212.

4. Hensen JJ, Van Breda Vriesman AC, Puylaert JBCM. Abdominal wall endometriosis: Clinical presentation and imaging features with emphasis on sonography. AJR. 2006;186:616-620. http://dx.doi.org/10.2214/AJR.04.1619

5. Blanco RG, Parithivel VS, Shah AK, Gumbs MA, Schein M, Gerst PH. Abdominal wall endometriomas. Am J Surg. 2003;185(6):596-598. http://dx.doi.org/10.1016/ S0002-9610(03)00072-2 